Stochastic Analysis: Classical and Quantum Perspectives of White Noise Theory 
This page intentionally left blank 


\title{
Stochastic Analysis:
}

Classical and Quantum

Perspectives of White Noise Theory

\section{Meijo University, Nagoya, Japan}

1-5 November 2004

\author{
Takeyuki Hida \\ Meijo University, Nagoya, Japan \\ editor
}




\section{Published by}

World Scientific Publishing Co. Pte. Ltd.

5 Toh Tuck Link, Singapore 596224

USA office: 27 Warren Street, Suite 401-402, Hackensack, NJ 07601

UK office: 57 Shelton Street, Covent Garden, London WC2H 9HE

\section{British Library Cataloguing-in-Publication Data}

A catalogue record for this book is available from the British Library.

\section{STOCHASTIC ANALYSIS: CLASSICAL AND QUANTUM} Perspectives of White Noise Theory

Copyright $(92005$ by World Scientific Publishing Co. Pte. Ltd.

All rights reserved. This book, or parts thereof, may not be reproduced in any form or by any means, electronic or mechanical, including photocopying, recording or any information storage and retrieval system now known or to be invented, without written permission from the Publisher.

For photocopying of material in this volume, please pay a copying fee through the Copyright Clearance Center, Inc., 222 Rosewood Drive, Danvers, MA 01923, USA. In this case permission to photocopy is not required from the publisher.

ISBN $981-256-526-4$

Printed in Singapore by B \& JO Enterprise 


\section{Preface}

We felt that time has come for a new epoch in stochastic analysis. Indeed various fields in mathematics as well as related fields in science continue to crossfertilize each other, while keeping good relationships with probability theory. There, dominant roles have been played by stochastic analysis (classical and quantum).

It therefore seems to be a good opportunity to organize a conference on important topics in stochastic analysis. Almost three decades has passed since white noise analysis was launched, we thus plan to have perspectives of the theory on this occasion.

Consequently, the conference "Stochastic Analysis: Classical and Quantum - Perspectives of White Noise Theory" took place at Meijo University, Nagoya, Japan for the period of November 1-5, 2004.

The organizers of the conference were extremely happy to see many eminent mathematicians having contributed to the success of the conference and cultivated new ideas. To our great pleasure, important papers presented at the conference are published in the Proceedings of the conference. As such, we are grateful to the respective authors and to the referees of those papers.

We acknowledge gratefully the general support of Meijo University and Ministry of Education, Culture, Sports, Science and Technology for the conference.

Special thanks are also due to Professors M. Röckner, L. Streit and T. Shimizu who gave financial support together with me for the publication of this Proceedings. Finally, I wish to note the great help given by members of the local organizing committee: Professors M. Hitsuda, S. Ihara, K. Saito and Si Si. In particular, it is to be mentioned that this Proceedings would not appear without the help of Professor Si Si who handled the aspect of editing. 
Organizing Committee of the Conference

\author{
Luigi Accardi \\ Takeyuki Hida \\ Hui-Hsiung Kuo \\ Masanori Ohya \\ Michael Röckner \\ Ludwig Streit
}




\section{Contents}

Preface $\quad$ v

\section{Part I}

White Noise Functional Approach to Polymer Entanglements

C. C. Bernido and M. V. Carpio-Bernido

White Noise Analysis, Quantum Field Theory, and Topology

A. Hahn

A Topic on Noncanonical Representations of Gaussian Processes

$Y$. Hibino

Integral Representation of Hilbert-Schmidt Operators on Boson Fock Space

U. C. Ji

The Dawn of White Noise Analysis

I. Kubo

White Noise Stochastic Integration

H. - H. Kuo

Connes-Hida Calculus and Bismut-Quillen Superconnections

$R$. Léandre and $H$. Ouerdiane

A Quantum Decomposition of Lévy Processes

Y.-J. Lee and H.-H. Shih

Generalized Entanglement and its Classification

T. Matsuoka

A White Noise Approach to Fractional Brownian Motion

D. Nualart 
Adaptive Dynamics in Quantum Information and Chaos M. Ohya

Micro-Macro Duality in Quantum Physics

$$
\text { I. Ojima }
$$

White Noise Measures Associated to the Solutions of Stochastic Differential Equations

H. Ouerdiane

A Remark on Sets in Infinite Dimensional Spaces with Full or Zero Capacity

$J$. Ren and M. Röckner

An Infinite Dimensional Laplacian in White Noise Theory K. Saitô

Invariance of Poisson Noise

Si Si, A. Tsoi and Win Win Htay

Nonequilibrium Steady States with Bose-Einstein Condensates S. Tasaki and T. Matsui

Multidimensional Skew Reflected Diffusions

G. Trutnau

On Quantum Mutual Type Entropies and Quantum Capacity N. Watanabe

\section{Part II}

White Noise Calculus and Stochastic Calculus

L. Accardi and A. Boukas 